



\section{Globalização e democracia: imigrações internacionais e os limites da cidadania nacional.}

\author{
Globalización y democracia: inmigra- \\ ciones internacionales y los límites de la \\ ciudadanía nacional.
}

\author{
Hélcio Ribeiro (Brasil) \\ helcioribeiro@uol.com \\ Doutor em direito pela Universidade de São Paulo, professor de \\ Sociologia Jurídica nos cursos de graduação e pós-graduação \\ em Direito Político e Econômico na Universidade Presbiteriana \\ Mackenzie em São Paulo.
}

\author{
Globalization and democracy: interna- \\ tional immigration and limits of national \\ citizenship.
}

\section{Resumen}

Aunque la democracia se haya transformado en una idea difundida hasta el cansancio por el mundo en las últimas décadas, también se verifica en la literatura especializada y en las investigaciones de opinión que el régimen democrático está en crisis. Este proceso aparentemente paradójico se deriva del hecho de que las nuevas democracias surgidas al final del siglo XX son desafiadas por dos factores importantes: la globalización económica y la creciente complejidad social. Con el declinar del Estado-Nación traído por el proceso de reestructuración del capitalismo a escala mundial, los mecanismos políticos y jurídicos de intervención económica, distribución de la renta, desarrollo nacional y protección de los derechos del ciudadano, sufren un radical debilitamiento. Por otro lado la globalización intensifica y facilita el desplazamiento poblacional y la migración internacional.

\section{Resumo}

Embora a democracia tenha se transformado em uma idéia difundida à exaustão pelo mundo nas últimas décadas, também se verifica na literatura especializada e nas pesquisas de opinião que o regime democrático está em crise. Este processo aparentemente paradoxal decorre do fato de que as novas democracias surgidas no final do século XX são desafiadas por dois fatores importantes: a globalização econômica e a crescente complexidade social. Com o declínio do Estado-Nação trazido pelo processo de reestruturação do capitalismo em escala mundial, os mecanismos políticos e jurídicos de intervenção econômica, distribuição da renda, desenvolvimento nacional e proteção dos direitos do cidadão, sofrem um radical enfraquecimento. Por outro lado a globalização intensifica e facilita o deslocamento populacional e a migração internacional.

\begin{abstract}
Although democracy has become an endlessly widespread idea around the world in recent decades, is also verified in specialized literature and opinion research that the democratic regime is in crisis. This apparently paradoxical process stems from the fact that the new democracies that emerged at the end of the twentieth century are challenged by two important factors: economic globalization and increasing social complexity. With the decline of the nation- state brought by the restructuring of capitalism at a global scale, political and legal mechanisms of economic intervention, income distribution, national development and protection of the citizens' rights, undergo a radical weakening. On the other hand, globalization intensifies and facilitates population displacement and international migration.
\end{abstract}


Palabras clave: Globalización, democracia, inmigraciones, ciudadanía
Keywords: Globalization, democracy, immigration, citizenship

Palabras chave: Globalização, Democracia, imigração, cidadania

\section{Para citar este artículo / to cite this article / para citar este artigo:}

Ribeiro, Helcio (2012). Globalização e democracia: Imigrações internacionais e os limites da cidadania nacional. Panorama, VII (12), $39-51$. 


\section{Introducción}

Processos migratórios em escala mundial são antigos e também marcam o advento da sociedade moderna. O fenômeno da globalização, porém, estimula novas formas de deslocamento populacional, trazendo consigo reações que vão desde a tentativa de fortalecer os controles estatais nas fronteiras e aeroportos, como também o ressurgimento de nacionalismos, xenofobia e racismo no interior dos Estados nacionais. Se, por um lado, tendências integristas de alguns Estados evocam muitas vezes a soberania popular como forma de defesa das fronteiras nacionais, por outro lado, evocam a ideia de direitos humanos e intervenções humanitárias para ocupação militar de Estados ditatoriais, com apoio da ONU. Este fenômeno traz à tona problemas políticos e jurídicos relacionados à própria ideia de democracia e direitos humanos. A conciliação entre estas duas dimensões não é pacífica. Ela aponta para o paradoxo da democracia moderna, assentada simultaneamente nas ideias de direitos humanos e soberania popular, ideias muitas vezes contraditórias.

A partir de sua teoria da ação comunicativa, o pensador alemão Jürgen Habermas, busca superar o paradoxo sustentando a ideia de cooriginariedade dos direitos humanos e da soberania popular, entendo-os como duas dimensões de um mesmo acordo no qual os parceiros do direito atribuem-se mutuamente direitos voltados para a proteção da autonomia privada (direitos humanos) e da autonomia pública (soberania popular e os decorrentes direitos de participação. Nesta perspectiva, Habermas avança uma possível solução teórica para o paradoxo com base numa teoria do direito assentada na ideia de discurso. 0 presente artigo apresenta alguns aspectos importantes da formulação habermasiana e algumas críticas feitas ao seu posicionamento.

\section{1) Teoria elitista da democracia e democracia deliberativa}

A ampla difusão dos valores democráticos no século XX e mais ainda após o fim do socialismo soviético e da queda do muro de Berlim em 1989, foi acompanhada de uma antiga polêmica, sempre renovada, a respeito do alcance e do sentido dos regimes democráticos. A hegemonia liberal tem sido alvo de constantes críticas e novas teorias vêm procurando apontar alternativas a este modelo no plano normativo. As teorias deliberativas da democracia buscam superar os limites do modelo agregativo que se desenvolve a partir da obra de Schumpeter cuja pretensão descritiva abandona idéias como bem comum, vontade geral e povo, em favor da idéia de agregação de preferências dos indivíduos via partidos políticos que competem em um processo eleitoral visto como um instrumento de escolha da elite governante, desencorajando a participação popular mais ampla e distanciando-se da dimensão normativa da política democrática. ${ }^{1}$

O regime democrático, entendido de forma geral como a participação dos cidadãos nas decisões políticas, define os limites desta participação, estabelecendo legalmente quem pode e quem não pode participar da formação da vontade política. O desenvolvimento da democracia moderna se dá concomitantemente ao advento do EstadoNação, levando à idéia de cidadania nacional. Ao longo da evolução do Estado moderno, este definiu não somente

1 Chantal Mouffe, The Democratic Paradox, Verso, London and New York, ,pag, 82, 
fronteiras territoriais como também os limites simbólicos de pertencimento e exclusão. Freqüentemente o regime democrático conviveu, deste modo, com diversas formas de exclusão como: mulheres, negros, índios, etc. A exclusão do imigrante sempre foi inerente à própria noção de cidadania dentro desse contexto, pois o Estado moderno se consolida atribuindo direitos e deveres aos seus cidadãos, protegendo a nação das ameaças externas. Isso não quer dizer que o imigrante não tenha participado desse processo. De modo geral as políticas de imigração variaram muito entre períodos de abertura e fechamento ao estrangeiro conforme necessidades econômicas dos Estados.

O processo de globalização vem alterando essa relação entre o nacional e o imigrante na medida em que desigualdades sociais, guerras e catástrofes ambientais forçam cada vez mais os fluxos migratórios internacionais. Por outro lado a globalização também facilita a circulação internacional de trabalhadores e pessoas em geral em virtude da compressão do espaço ${ }^{2}$ causada pelo barateamento dos transportes e da formação de redes de proteção do imigrante, colocando em cheque a capacidade de controle desses fluxos a partir do Estado nacional que vê sua soberania questionada.

A globalização vem afetando também a capacidade do Estado de garantir direitos aos seus próprios cidadãos na medida em que os fluxos financeiros internacionais e políticas de privatização, associadas à reestruturação produtiva do capitalismo, aumentam as desigualdades entre classes e países ${ }^{3}$, estimulando o ressurgimento de tendências nacionalistas, xenófobas e fundamentalistas.

Faria aponta cinco conseqüências da reestruturação produtiva do capitalismo, responsáveis pelo enfraquecimento do Estado-nação. A primeira é a velocidade do desenvolvimento científico e tecnológico, convertido em força produtiva pela sociedade da informação, cada vez mais voltados para a busca do lucro no curto prazo e trazendo como conseqüência o aumento dos riscos ambientais e financeiros, não mais passíveis de controle pelos meios técnicos e jurídicos que caracterizaram a sociedade moderna. Como são produzidos por forças políticas e econômicas de dimensão transnacional é difícil identificar os responsáveis pelos danos, colocando em cheque a própria idéia de cidadania. A segunda é a redução da margem de manobra dos governos na formulação das políticas econômicas diante da financeirização da economia global e da ação de empresas transnacionais e agências de análise de risco que desafiam a soberania e a democracia dos países em desenvolvimento. ${ }^{4}$

A terceira conseqüência da reestruturação capitalista é a diferenciação sócio-econômica responsável pela formação de sistemas autoregulados que ultrapassam as fronteiras nacionais e dissolvem as formas centralizadas e hierárquicas de poder tradicionais. A quarta está relacionada à reorganização industrial estimulada pelo advento do pós-fordismo e fragmentação da produção cuja flexibilidade nos sistemas de automação e gestão empresarial tem forte impacto na divisão internacional do trabalho, propiciando o surgimento de fenômenos como a relocalização industrial a partir de estratégias que favorecem a busca de mão de obra mais barata, incentivos fiscais, neutralização

2 David Harvey, Condição Pós-moderna. São Paulo, Edições Loyola, 1992.

3 José Eduardo Faria, Direito e Conjuntura, São Paulo, Saraiva, 2008.

4 José Eduardo Faria. Direito e Conjuntura, São Paulo, Saraiva, 2008, pags. 14-23. 
de pressões trabalhistas e das leis de proteção ambiental. ${ }^{5}$ A quinta e última consequência da reestruturação do capitalismo se refere à própria crise do Estado-nação do ponto de vista cultural e étnico com o advento de processos migratórios e surgimento de novas e complexas formas de identidade multicultural. ${ }^{6}$

O desenvolvimento deste processo coloca em risco a sobrevivência da própria democracia liberal', desafiando as propostas de reformulação das bases normativas do regime democrático que, grosso modo, ainda estão assentadas no modelo liberal que relaciona democracia e Estado nacional. As teorias deliberativas embora apontem a necessidade de ampliação da participação e busquem uma nova compreensão das relações entre sociedade civil e instituições políticas, esbarram na ambivalência do Estado-nação e da democracia moderna responsáveis por uma concepção restrita de cidadania. Esta é incapaz de dar conta dos conflitos que surgem por conta do próprio processo de globalização que estimula a circulação internacional de pessoas, trazendo à tona manifestações de xenofobia e racismo. As teorias deliberativas, por exemplo, não incluem o tema do imigrante e do direito de imigração ${ }^{8}$, a despeito do desenvolvimento de uma ampla legislação internacional de direitos humanos e de proteção de imigrantes, legais ou não, refugiados e turistas. Este processo não afeta apenas a situação do imigrante, legal ou ilegal, ela coloca em cheque própria democracia liberal na medida em que esta desenvolveu-se, modernamente, a partir da constituição do Estado nacional e de uma clara distinção entre o cidadão nacional e o outro, entre aquele que está dentro e aquele que está fora. Com o advento da sociedade global imperial estas distinções entram em declínio, bem como as dicotomias natural/social, público/privado: "Em contraste com o imperialismo, o Império não estabelece um centro territorial de poder, nem se baseia em fronteiras ou barreiras fixas. É um aparelho de descentralização e desterritorialização do geral que incorpora gradualmente o mundo inteiro dentro de suas fronteiras abertas e em expansão”.?

Diante da crise da democracia assentada no Estado-Nação, vem se desenvolvendo, no entanto, um ampla literatura a respeito da formação de uma sociedade civil transnacional e de uma cidadania mundial que esbarram no ceticismo de muitos analistas que ainda vêem no Estado nacional a solução dos problemas da sociedade global ${ }^{10}$.

Na teoria discursiva da democracia desenvolvida pelo filósofo alemão Jurgen Habermas encontra-se a mais importante e influente tentativa de elaboração da teoria deliberativa da democracia que, embora leve a sério o problema da inclusão, apresenta solução parcial para a questão do imigrante e dos choques culturais pelos quais passa a Europa e o mundo globalizado.

5 José Eduardo Faria, Direito e Conjuntura, São Paulo, Saraiva, 2008, pag. 26.

6 José Eduardo Faria, Direito e Conjuntura, São Paulo, Saraiva, 2008,pag.28.

7 Jean-Marie Guéhenno, O fim da democracia, Rio de janeiro, Bertrand Brasil, 1994;Luciano Canfora, A democracia: História de uma Ideologia, Coimbra, Edições 70, 2007; Giorgio Agamben, O Estado de Exceção.

8 Reis, Rosana Rocha. Soberania, Direitos Humanos e Migrações Internacionais.

9 Antonio Negri e Michael Hardt. Império, Rio de Janeiro, Record, 2001, pag. 12.

10 Fernando de Souza. A Democracia: face política da globalização?, Revista Brasileira de Política Internacional, v. 49, n.1, Brasília, jan-jun. 2006; Rafael Duarte Villa; Ana Paula Baltasar Tostes, Democracia Cosmopolita versus Política Internacional, Lua Nova: Revista de Cultura e Política, n. 66, São Paulo, 2006. 


\section{A congruência entre autonomia pública e privada na teoria do discurso: republicanismo, liberalismo e procedimentalismo}

Na teoria do discurso habermasiana a coesão entre Estado de direito e democracia decorre da idéia da equiprimordialidade de ambas idéias, de modo que uma não se sobreponha à outra. Nem o princípio da soberania popular deve ter primazia sobre os direitos humanos, nem este deve ter primazia sobre aquele. A concepção republicana, presente na história da filosofia de Aristóteles até a Renascença, dá primazia à autonomia pública dos cidadãos ao passo que a tradição liberal valoriza os direitos humanos como forma de evitar os riscos de uma tirania da maioria. ${ }^{11}$ Segundo Habermas, embora Kant e Rousseau tenham tentado desenvolver uma teoria em que soberania e direitos humanos se interpretem mutuamente, nenhum dos dois levou até o fim esta perspectiva:

Eles ignoram a intuição que haviam pretendido trazer para junto do conceito: a idéia dos direitos humanos, que se enuncia no direito em relação a liberdades de ação subjetivas e iguais, não pode nem simplesmente impingirse ao legislador soberano como uma barreira externa, nem se deixar instrumentalizar como requisito funcional para os fins desse mesmo legislador. ${ }^{12}$

Para superar o dilema Habermas propõe encarar o processo democrático como mecanismo de legitimação do direito a partir da teoria do discurso. A vontade política racional, embasada em arranjos comunicativos, depende, deste modo, das condições jurídicas em que se institucionaliza o processo comunicativo capaz de criar direito legítimo.

A almejada coesão interna entre direitos humanos e soberania popular consiste assim em que a exigência de institucionalização jurídica de uma prática civil do uso público das liberdades comunicativas seja cumprida justamente por meio dos direitos humanos. Direitos humanos que possibilitam o exercício da soberania popular não se podem impingir de fora, como uma restrição. ${ }^{13}$

Isto implica estabelecer uma relação entre direito e política que leva a uma revisão do conceito de soberania. No Estado de Direito a soberania não se encarna mais em um sujeito identificado, nem na reunião dos cidadãos, mas na formação da vontade política na esfera pública onde circula o poder comunicativo, intersubjetivamente. $\mathrm{O}$ poder político assume dupla dimensão: no poder comunicativo da esfera pública e no poder administrativo que toma decisões. ${ }^{14}$

Ao mesmo tempo, os direitos humanos garantem a autodeterminação dos cidadãos no plano privado, uma vez que, como autores do direito, eles são também seus destinatários. Visto deste ângulo, a teoria do discurso

11 A inclusão do outro, pag. 299.

12 A inclusão do outro, pag. 299.

13 A inclusão do outro, pag, 300.

14 Direito e Democracia, vol. I, pag. 173. 
dissolve a contradição aparente entre autonomia pública e autonomia privada dos cidadãos. Os direitos humanos não são vistos, nesta perspectiva, como fatos morais que o legislador é levado a positivar pois os cidadãos só podem garantir sua autonomia a partir da linguagem do direito, como sujeitos do direito.

Não há direito algum sem a autonomia privada de pessoas do direito. Portanto, sem os direitos fundamentais que asseguram a autonomia privada dos cidadãos, não haveria tampouco um médium para a institucionalização jurídica das condições sob as quais eles mesmos podem fazer uso da autonomia pública ao desempenharem seu papel de cidadãos do Estado. Dessa maneira, a autonomia privada e a pública pressupõe-se mutuamente, sem que os direitos humanos possam reivindicar um primado sobre a soberania popular, nem essa sobre aquele. ${ }^{15}$

Segundo Habermas essa coesão interna entre Estado de direito e democracia foi ofuscado pelo predomínio ora do paradigma jurídico liberal, ora pelo paradigma jurídico do Estado social, ambos voltados para o desenvolvimento de uma sociedade econômica e produtivista. A concepção procedimentalista, por sua vez, busca dissolver a contradição partindo da equiprimordialidade dos direitos humanos e do princípio da soberania popular, tornando coerente a coexistência da autonomia pública e da autonomia privada a partir da autolegislação surgida da comunicação intersubjetiva da esfera pública, cristalizada em normas de direito positivo pelo poder administrativo do Estado.

\section{Estado-nação: direitos humanos contra a cidadania?}

Apesar da dificuldade em definir com exatidão o que é uma Nação ${ }^{16}$ é certo que esta idéia teve um papel fundamental nos processos modernos de integração social, ao garantir a coesão entre indivíduos e grupos que já não tinham mais qualquer ligação com os laços estamentais tradicionais e, simultaneamente, garantir novas bases de legitimação para o Estado secularizado, cuja autoridade não podia mais fazer apelo à sua antiga base religiosa. Segundo Habermas o Estado moderno precisou mobilizar politicamente a população apelando não apenas à soberania popular e aos direitos humanos, mas a uma idéia com força suficiente para mobilizar as consciências do ponto de vista moral: a idéia de nação. Deste modo a nação não é histórica e culturalmente anterior à constituição política dos cidadãos autônomos mas o resultado de um compromisso cosmopolita que implica garantir a segurança e a liberdade interna em face às ameaças externas, ou seja, ela assume uma dupla face: "Ao passo que a nação dos cidadãos ligados ao Estado, fruto da vontade, é fonte de legitimação democrática, a nação de compatriotas, gerada de maneira espontânea, provê a integração social”. ${ }^{17}$

Habermas aponta, assim, uma ambivalência no Estado nacional moderno, resultado da tensão entre o universalismo da comunidade jurídica igualitária e o particularismo da comunidade histórica com propensão para um estado de guerra quase permanente, que só pode ser resolvida quando se dá primazia à autocompreensão cosmopolita da nação, cristalizada no Estado de direito democrático, em relação à concepção etnocêntrica e naturalista de nação:

15 A inclusão do outro, pag. 301

16 Eric Hobsbawm. Nações e nacionalismo.

17 A inclusão do outro, pags. 134 e segs. 
O Estado nacional deve seu êxito histórico à circunstância de ter substituído as débeis alianças corporativas da sociedade pré-moderna pela coesão solidária dos cidadãos. Mas essa conquista republicana passa a correr perigo se, ao invés, a força integrativa da nação de cidadãos for atribuída a um dado que se pretenda anterior à política, ou seja, a existência de um povo constituído por via natural e, portanto, a algo independente da formação política da opinião e da vontade dos próprios cidadãos. ${ }^{18}$

A dimensão bifronte da nacionalidade leva Habermas a sustentar que políticas de imigração devem combinar a dimensão política com a dimensão cultural da cidadania. O reconhecimento dos direitos do imigrante, interpretados politicamente numa perspectiva universalista, não deve levar à exigência de abandono da sua cultura, ao mesmo tempo que o imigrante deve respeitar a cultura política de sua nova pátria, pois "a aculturação política exigida não se estende à totalidade de sua socialização". ${ }^{19}$

A interpretação universalista dos direitos da cidadania é um requisito primordial para impedir que a comunidade se feche em si mesma e se sinta ameaçada pelo imigrante. Só desta forma é possível, segundo o filósofo alemão, o caminho para uma cidadania mundial que, embora esteja longe de ser atingida, já pode ser vislumbrada nas diversas redes e movimentos de natureza global que vêm colocando em cheque a soberania do Estado-Nação desde inícios dos anos noventa do século passado. O autor sugere, em um texto escrito num momento em que o fim da União Soviética e a reunificação da Alemanha estimularam intensos fluxos migratórios e a reorganização territorial do velho continente, que os Estados europeus se unam em torno de uma política liberal de imigração ${ }^{20}$, desenvolvendo um diálogo não imperialista com as demais culturas. Fica claro, porém, que o autor sugere um papel importante para a Europa do século XXI no processo de criação de uma nova ordem mundial após a decadência dos impérios ${ }^{21}$, deixando entrever um viés etnocêntrico em sua perspectiva.

No plano interno das nações, a teoria do discurso contribui para repensar o problema da inclusão do imigrante ao salientar a dimensão política da constituição da idéia de nação.

Mas ela também apresenta alguns limites importantes. Em primeiro lugar não é clara no que diz respeito à articulação e eventuais contradições entre a dimensão política e a cultural da cidadania pois a inclusão do imigrante requer uma ampliação do acordo político em detrimento da perspectiva cultural. Algo necessário mas difícil de se conseguir em face da força das tradições. O desenvolvimento de uma cidadania multicultural exige uma disposição política de elaborar novas formas de regulação voltadas para uma política de reconhecimento:

“...a organização de uma "cidadania multicultural” exige políticas e regulamentações que abalam a fundamentação nacional da solidariedade dos cidadãos transformada em uma segunda natureza. Nas sociedades multiculturais, torna-se necessária uma "política de reconhecimento", porque a identidade de cada cidadão singular

\footnotetext{
18 A inclusão do outro, pag. 138

19 Direito e Democracia, vol II, pag.304.

20 Direito e Democracia, vol. II, pags. 304 e305.

21 Direito e Democracia, vol. II, pag. 297
} 
está entretecida com as identidades coletivas e não pode prescindir da estabilização em uma rede de reconhecimentos recíprocos. ${ }^{22}$

A concepção política liberal em que está assentada aposta muitas fichas na racionalidade dos acordos. Desta forma um requisito fundamental para o desenvolvimento de sociedades multiétnicas e democráticas é o reconhecimento, em cada uma delas, dos limites de suas próprias tradições culturais. Seja no plano das relações internacionais seja no plano interno do Estado-nação, o reconhecimento e a inclusão do outro depende de uma política de direitos humanos que seja capaz de superar os limites da concepção hegemônica liberal que vêm servindo de pretexto para impor os interesses do mercado global com o argumento de levar a democracia a países que vivem sob a opressão de regimes ditatoriais e pré-modernos, ou seja, que não compartilham as tradições ocidentais e, principalmente, européias de democracia e direitos humanos. ${ }^{23}$ Seguindo os passos da hermenêutica diatópica proposta por Boaventura de Souza Santos, cada cultura precisa reconhecer sua incompletude.

Um projeto de transformação cosmopolita e contra-hegemônico depende das seguintes premissas. Em primeiro lugar superar o debate entre universalismo e relativismo cultural. Em segundo reconhecer que todas as culturas possuem concepções de dignidade humana, ainda que não a desenvolvam a partir de alguma teoria de direitos humanos. Em terceiro lugar reconhecer que todas as culturas são incompletas e problemáticas em suas concepções de dignidade humana. Em quarto lugar nenhuma cultura é monolítica uma vez que comportam diferentes concepções de dignidade humana em seu interior. Em quinto lugar todas as culturas dividem pessoas e grupos entre dois princípios diferentes de pertencimento hierárquico: o princípio da igualdade e o princípio da diferença. $\mathrm{O}$ primeiro funciona a partir de unidades homogêneas como os estratos econômicos e o segundo opera a partir de diferenças étnicas, sexuais, religiosas, etc. Uma concepção transformadora e contra-hegemônica deve tentar distinguir as duas formas de luta. ${ }^{24}$

\section{Considerações finais}

O advento da globalização estimula a circulação de pessoas e enfraquece o papel dos Estados no controle dos fluxos migratórios. Este processo, aliado ao crescimento das desigualdades entre classes e países, não favorece, no entanto, uma inclusão democrática do imigrante em seus novos contextos. Ao contrário, a crise da democracia se aprofunda na medida em que as concepções deliberativas não parecem ser suficientes para dar conta da escalada de novos nacionalismos e formas de exclusão acentuadamente xenófobas. Embora as teorias deliberativas busquem a ampliação da participação e o estímulo à cidadania ativa no plano nacional, a questão do imigrante não é tratada. O tema do imigrante é importante porque mostra os limites da concepção tradicional de democracia e cidadania centrada no Estado-Nação. As teorias deliberativas da democracia reproduzem esta limitação mesmo quando apontam para a necessidade de repensar o problema da inclusão a partir da idéia de cidadania mundial.

22 Jurgen Habermas, A Constelação Pós-nacional: ensaios políticos, São Paulo, Littera Mundi, 2001, pag.94.

23 Eric Hobsbawn, Globalização, Democracia e Terrorismo, São Paulo, Companhia das Letras, 2007.

24 Boaventura de Souza Santos, Para uma concepção intercultural de direitos humanos, in A Gramática do Tempo: para uma nova cultura política, São Paulo, Cortez, 2006, pags. 445 a 447. 
A teoria do discurso habermasiana avança quando propõe a equiprimordialidade dos conceitos de soberania popular e direitos humanos na autocompreensão do Estado democrático de direito, mas é insuficiente e contraditória ao sugerir a necessidade de ampliar a cidadania para um espaço mundial, pois não leva em consideração o fato de que este último pressupõe uma redução do próprio conceito de soberania popular. Ou seja, se no plano interno a existência de uma dimensão política da nação convive com a dimensão cultural, o desenvolvimento da cidadania mundial implicaria a necessidade de redução da dimensão cultural para que um acordo político mais amplo abra espaço para a sociedade civil internacional. Em outras palavras, a idéia de cidadania mundial prescinde de uma conceituação melhor da idéia de autolegislação na perspectiva da esfera pública mundial, ainda incipiente. Habermas percebeu o problema e em seus últimos escritos vêm desenvolvendo uma concepção de cidadania a partir da idéia de uma sociedade civil mundial..$^{25}$

A superação do dilema tem, na idéia de hermenêutica diatópica, um complemento imprescindível para pensar uma ordem global contra-hegemônica e evitar que a concepção naturalista e etnocêntrica da nação se sobreponha à dimensão política e acabe servindo a interesses falsamente universais e imperiais.

25 Jürgen Habermas, A Constelação Pós-Nacional: ensaios políticos, São Paulo, Littera Mundi, 2001. 


\section{Referências}

1. Canfora, 2007 Luciano. A democracia: História de uma Ideologia, Coimbra, Edições 70.

2. Faria, 1999 José Eduardo. O direito na economia globalizada, São Paulo, Malheiros.

3. ___ 2008 Direito e Conjuntura, São Paulo, Saraiva.

4. Géhenno, 1994 Jean-Marie. O fim da democracia, Rio de Janeiro, Bertrand Brasil.

5. Habermas, 1997 Jurgen. Direito e Democracia: entre faticidade e validade, vol. I e II, Rio de Janeiro, Tempo Brasileiro.

6. _ـ 2002 A inclusão do outro. São Paulo, Edições Loyola.

7. _ـ_ 2001 A Constelação Pós-nacional: ensaios políticos, São Paulo, Littera Mundi.

8. Harvey, 1992 David. Condição Pós-moderna. São Paulo, Edições Loyola.

9. Hobsbawm, 1990 Eric. Nações e nacionalismo desde 1780, Rio de Janeiro, Paz e Terra.

10. _ـ 2007 Globalização, Democracia e Terrorismo, São Paulo, Companhia das Letras.

11. Mouffe, 2009 Chantal. The Democratic Paradox, Verso, London and New York.

12. Negri, 2001 Antonio Ehardt, Michael. Império, Rio de Janeiro, Record.

13. Reis, 2004 Rosana Rocha. Soberania, Direitos Humanos e Migrações Internacionais, Revista Brasileira de Ciências Sociais, vol. 19, no. 55.

14. Santos, 2006 Boaventura de Souza Para uma concepção intercultural de direitos humanos, in A Gramática do Tempo: para uma nova cultura política, São Paulo, Cortez.

15. Souza, 2006 Fernando de. A Democracia: face política da globalização?, Revista Brasileira de Política Internacional, v. 49, n.1, Brasília, jan-jun.

16. Villa, 2006 Rafael Duarte; TOSTES, Ana Paula Baltasar, Democracia Cosmopolita versus Política Internacional, Lua Nova: Revista de Cultura e Política, n. 66, São Paulo. 